\title{
Effects of Variable Viscosity and Thermal Conductivity of Unsteady Micropolar Fluid under Mixed Convection in Presence of Uniform Magnetic Field on Stretching Surface
}

\author{
Indira Baruah \\ Department of Mathematics, Tinsukia College, \\ Tinsukia, Assam, India
}

\author{
G. C. Hazarika \\ Department of Mathematics, Dibrugarh University, \\ Assam, India
}

\begin{abstract}
In the paper, an analysis is performed to study the effect of temperature dependent viscosity and thermal conductivity of unsteady viscous incompressible boundary layer micropolar fluid flow under mixed convection. The flow past is to be studied over a stretching sheet in presence of viscous dissipation. In the process of study, partial differential equations governing the flow have been transformed into ordinary differential equations in dimensionless form using similarity transformation and solved numerically by using Runge-Kutta shooting method. The effects of various important parameters of the problem concerned like viscosity, thermal conductivity, micro-rotation, unsteadyness of the fluid on velocity and temperature within the boundary layers are obtained. The results are represented graphically. The skin friction, Nusselt numbers are also computed, analysed and given in tabular form.
\end{abstract}

\section{Keywords}

Micropolar Fluid, Boundary Layer, Unsteady flow, Mixed convection, Stretching sheet.

\section{INTRODUCTION}

The micropolar fluids are non-Newtonian fluids firstly introduced by Eringen [1,2], which cannot be described by classical Navier-Stokes theory. The extension of this theory and applications can be found in the literature of Ariman et al. [15], Lukaszewicz [6] and Eringen[1,2]. Micropolar fluids contain dilute suspension of rigid macromolecules with individual motion that support stress and body moments influenced by spin inertia. Lots of pollutants and microconstituents are present in our biosphere, so the study on micrpolar fluid in the present context of environment is very important. Sakiadis[3] had studied the boundary layer concept and then Peddison and Mc Nitt[7]

derived the boundary layer theory for micropolar fluid which is important in a number of technical processes. Due to the importance of heat transfer on the flow the field of micropolar fluid attracted many researchers and accordingly contributions were found towards free, force and mixed convection heat transfer cases of micropolar fluid in different environments. Many classical flows are being re-examined to determine the effects of fluid microstructure.Thestudyofmagnetohydrodynamics(MHD) of electrically conducting fluid in a micrpolar fluid is being encountered in Geophysics, Astrophysics as well as in Engineering applications such as MHD generators, plasma studies, nuclear reactors and geothermal energy extractions. Gorla [13] studied mixed convection flow of micropolar fluid from a vertical surface with uniform heat flux. Oianrewaju[11] studied the thermal radiation effect towards stagnation point on vertical plate in micropolar fluid. All the above cases are in steady state but fluid is not always in steady state and it will become unsteady due to impulsive change in the surface velocity or temperature or due to time dependent variation in them. Hence, it has become important to study unsteady state of fluid flow. Hayat[14] studied the radiation effect of micropolar fluid with heat and mass transfer in unsteady state. Lasker[9], El Aziz[10] discussed unsteady behaviour of micropolar fluid over a stretching sheet

. Many researchers considered such type of problems and solved them using various methods. The nano-fluid flow over an unsteady stretching surface in the presence of thermal radiation was examined by Das et al.[8] . Hazarika and Phukan [4] studied the effect of variable viscosity and thermal conductivity on MHD flow of micropolar fluid in a continuous moving flat plate. Thakur et al.[12]also investigated the effects of variable viscosity and thermal conductivity on unsteady free convection heat and mass transfer MHD flow of micropolar fluid in presence of magnetic field.

Here, the aim of the paper is to study the behaviour of unsteady micropolar fluid under mixed convection in presence of magnetic field on a stretching surface. The fluid viscosity and thermal conductivity are assumed to be inverse linear function of temperature. The governing partial differential equations are reduced to ordinary differential equations by similarity transformations. The problem is then solved numerically using Runge-Kutta shooting algorithm with iteration process.

\section{MATHEMATICAL MODEL}

We consider two dimensional unsteady MHD free convection boundary layer micropolar fluid flow past where a semi infinite vertical plate $\mathrm{y}=0$. The $\mathrm{X}$-axis is taken along the heated plate in upward direction and $\mathrm{Y}$-axis which is normal to $\mathrm{X}$-axis is in horizontal position. The plate is immerged in the micropolar fluid with temperature $\mathrm{T}$. The fluid properties are assumed to be constant, except for the fluid viscosity and thermal conductivity. Let us consider a magnetic field of the form $\left(\mathrm{B}_{\mathrm{x}}, \mathrm{B}_{0}, 0\right)$ which is acting along $\mathrm{x}$ and $\mathrm{y}$ directions. Considered that the sheet is being stretched with the velocity $\mathrm{U}_{\mathrm{w}}$ along $\mathrm{x}$-axis, keeping origin fixed and the temperature of the sheet consider as $\mathrm{T}_{\mathrm{w}}$, where

$$
U_{w}=\frac{a x}{1-\alpha t} \quad \text { and } \quad T_{w}=T_{\infty}+\frac{b x}{(1-\alpha t)^{2}}
$$

$a, b$ and $\alpha$ are constants. These relation hold only if $\mathrm{t}<\alpha$ 1 . The prescribed situation can be represented graphically as below: 


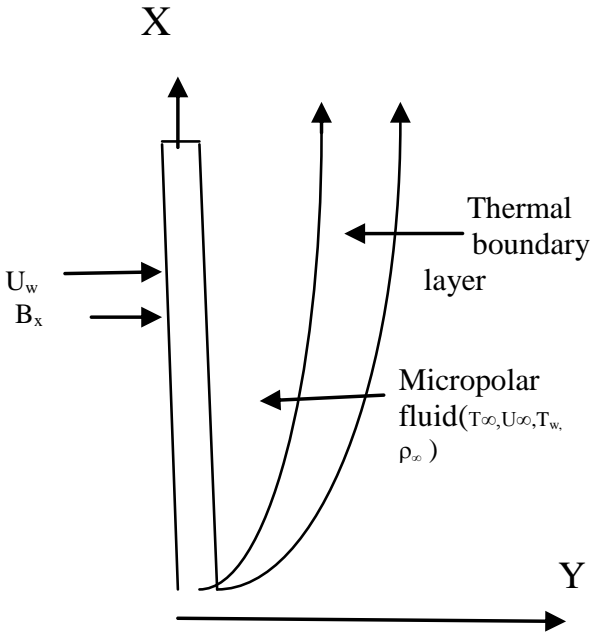

Fig 1: Geometrical representation of the flow Under these above assumptions the governing equations appear as follows:

The equation of continuity:

$$
\frac{\partial u}{\partial x}+\frac{\partial v}{\partial y}=0
$$

The linear momentum equation

$$
\begin{aligned}
\frac{\partial u}{\partial t} & +u \frac{\partial u}{\partial x}+v \frac{\partial u}{\partial y}=\left(\frac{\mu+\kappa}{\rho}\right) \frac{\partial^{2} u}{\partial y^{2}}+\frac{1}{\rho} \frac{\partial \mu}{\partial y} \frac{\partial u}{\partial y}+\frac{\kappa}{\rho} \frac{\partial N}{\partial y} \\
& +g \beta\left(T-T_{\infty}\right)-\frac{\sigma}{\rho} B_{0}\left(u B_{0}-v B_{x}\right)
\end{aligned}
$$

The angular momentum equation:

$$
\frac{\partial N}{\partial t}+u \frac{\partial N}{\partial x}+v \frac{\partial N}{\partial y}=\frac{\gamma}{\rho j}\left(\frac{\partial^{2} N}{\partial y^{2}}\right)-\frac{\kappa}{\rho j}\left(2 N+\frac{\partial u}{\partial y}\right)
$$

The energy equation:

$$
\begin{gathered}
\rho C_{p}\left(\frac{\partial T}{\partial t}+u \frac{\partial T}{\partial x}+v \frac{\partial T}{\partial y}\right)=\frac{\partial \lambda}{\partial y} \frac{\partial T}{\partial y}+\lambda \frac{\partial^{2} T}{\partial y^{2}}+ \\
(\mu+\kappa)\left(\frac{\partial u}{\partial y}\right)^{2}+\sigma\left(u B_{0}-v B_{x}\right)^{2}
\end{gathered}
$$

The magnetic induction equation:

$$
\frac{\partial B_{x}}{\partial t}=B_{0}-v \frac{\partial B_{x}}{\partial y}-B_{x} \frac{\partial v}{\partial y}+\eta_{m} \frac{B_{x}}{v} \frac{\partial^{2} v}{\partial x^{2}}+\eta_{m} \frac{\partial^{2} B_{x}}{\partial y^{2}}
$$

with boundary condition:

$$
\left.\begin{array}{l}
u=U_{w}, v=0, N=0, T=T_{w}, B_{x}=B_{0} \text { at } y=0 \\
u \rightarrow 0, v \rightarrow 0, N \rightarrow 0, T \rightarrow T_{\infty}, B_{x}=0 \text { at } y \rightarrow \infty
\end{array}\right\}
$$

Here $\mathrm{u}$ and $\mathrm{v}$ are velocity components along $\mathrm{x}$ and $\mathrm{y}$-axes, $\mu$ and $k$ are the coefficients of viscosity and thermal conductivity respectively of the fluid, $C_{p}$ is the specific heat at constant pressure and $\sigma$ is the electrical conductivity, $a$ is the constant stretching rate, $T_{\infty}$ is the temperature far away from the stretching sheet and $T$ is the temperature inside the boundary layer. $j=\left(\frac{v}{c}\right)$ is the microinertia per unit mass, $\gamma=\left(\mu+\frac{\kappa}{2}\right) j$ and $\kappa$ are the spin gradient viscosity and vortex viscosity.

The fluid viscosity is assumed to be inverse linear function of temperature (Lai and Kulacki [4]) as

$$
\left.\begin{array}{l}
\frac{1}{\mu}=\frac{1}{\mu_{\infty}}\left[1+\delta\left(T-T_{\infty}\right)\right] \\
\frac{1}{\mu}=b\left(T-T_{r}\right) \\
\text { where } b=\frac{\delta}{\mu_{\infty}} \quad, T_{r}=T_{\infty}-\frac{1}{\delta}
\end{array}\right\}
$$

Similarly, consider the variation of thermal conductivity as

$$
\left.\begin{array}{l}
\frac{1}{\lambda}=\frac{1}{\lambda_{\infty}}\left[1+\xi\left(T-T_{\infty}\right)\right] \\
\frac{1}{\lambda}=c\left(T-T_{k}\right) \\
\text { where } c=\frac{\xi}{\lambda_{\infty}} \quad, T_{k}=T_{\infty}-\frac{1}{\xi}
\end{array}\right\}
$$

Also b, c, $T_{r}$ and $T_{k}$ are constants and their values depend on the reference state and thermal properties of fluid i.e., $v$ and $\lambda$ . In general $b, c>0$ for liquids and $b, c<0$ for gases.

$$
\begin{gathered}
u=\frac{\partial \psi}{\partial y}, \quad v=-\frac{\partial \psi}{\partial x} \\
\psi=\sqrt{\frac{a v}{1-\alpha t}} x f(\eta), \quad \eta=\sqrt{\frac{a}{v(1-\alpha t)}} y, \\
N=\left(\frac{a}{(1-\alpha t)}\right)^{3 / 2} \frac{x}{\sqrt{v}} h(\eta), B(t)=\sqrt{\frac{a v}{1-\alpha t}} g(\eta)
\end{gathered}
$$




$$
\theta(\eta)=\frac{T-T_{\infty}}{T_{w}-T_{\infty}} \quad, \quad B_{0}=\sqrt{\frac{a v}{1-\alpha t}}
$$

On substitution of the above transformation in the equation (2) - (6), it becomes

$$
\begin{aligned}
& (1+\Delta) f^{\prime \prime \prime}=\frac{\theta^{\prime}}{\theta-\theta_{r}} f^{\prime \prime}+\frac{A}{2}\left(2 f^{\prime}+\eta f^{\prime \prime}\right)-f f^{\prime \prime} \\
& +f^{\prime 2}-K g^{\prime}-\zeta \theta+M^{2}\left(R_{e}^{-1} f^{\prime}+R_{e}^{-\frac{3}{2}} f h\right.
\end{aligned}
$$

$g^{\prime \prime}=\frac{A}{2 \Delta_{1}}\left(3 g+\eta g^{\prime}\right)+\frac{1}{\Delta_{1}}\left\{f^{\prime} g-f g^{\prime}+\Delta B^{*}\left(2 g+f^{\prime \prime}\right)\right\}$

$$
\begin{aligned}
& \theta^{\prime \prime}=\frac{1}{2} A P_{r}\left(\eta \theta^{\prime}+4 \theta\right)+P_{r}\left(f^{\prime} \theta-f \theta^{\prime}\right)+\frac{1}{\theta-\theta_{k}} \theta^{\prime 2}- \\
& (1+\Delta) P_{r} E_{c} f^{\prime / 2}-M^{2} E_{c} R_{e}^{-1}\left(f^{\prime 2}+2 R_{e}^{-\frac{1}{2}} f f^{\prime} h+R_{e}^{-1} f^{2} h^{2}\right)
\end{aligned}
$$

$h^{\prime \prime}=\frac{1}{2} A P_{m}\left(h+\eta h^{\prime}\right)-P_{m}\left(h+R_{e}^{\frac{1}{2}}\right) f^{\prime \prime}+P_{m} f h^{\prime}$

Where $\Delta=\kappa / \mu$ micropolar parameter , $\mathrm{A}=\alpha / \mathrm{a}$ unsteady parameter, $\Delta_{1}=\frac{\gamma}{\mu j}$ is the material constant.

$\zeta=\mathrm{G}_{\mathrm{r}} / \operatorname{Re}_{\mathrm{x}}{ }^{2}=\mathrm{g} \beta \mathrm{b} / \mathrm{a}^{2}$ mixed convection or buoyancy parameter.

$G_{r}=\frac{g \beta\left(T_{w}-T_{\infty}\right) x^{3}}{v^{2}}, \operatorname{Re}_{x}=\frac{U_{w} x}{v}$ local Grashof number and local Reynolds number.

$M=\frac{\sigma B_{0}^{2}}{\rho a}$ magnetic parameter.

$B^{*}=\frac{v(1-\alpha t)}{j b}=\frac{v x}{j U_{w}}$ dimensionless parameter.

$P_{r}=\frac{\mu c_{p}}{k}$ Prandtl number

$P_{m}=\frac{v}{n_{m}}=\mu_{0} \sigma v \quad$ magnetic Pandtl Number

Boundary conditions(BC) becomes
In this problem skin friction coefficient $C_{f}$ and the Nusselt number $N_{u}$ are two important physical quantities which give the rate of wall shear stress and rate of heat transfer for the surface respectively. These are given by:

$$
C_{f}=\frac{2 \tau_{w}}{\rho U^{2}} \text {, where the wall shear stress } \tau_{w} \text { for }
$$

micropolar boundary layer flow is given by $\tau_{w}=\left[(\mu+k) \frac{\partial u}{\partial y}+k N\right]_{y=0}$

The Nusselt number is given by $N_{u}=\frac{x q_{w}}{\lambda_{\infty}\left(T_{w}-T_{\infty}\right)}$ where $\mathrm{q}_{\mathrm{w}}$ heat transfer from surface is given by:

$$
q_{w}=-\lambda\left(\frac{\partial T}{\partial y}\right)_{y=0}
$$

In our case it becomes:

$$
C_{f}=2 R_{e}^{-\frac{1}{2}}\left[(1+\Delta) f^{\prime \prime}(0)\right]
$$

And the Nusselt No :

$$
N_{u}=-R_{e}^{\frac{1}{2}} \theta^{\prime}(0)
$$

\section{RESULTS AND DISCUSSIONS}

The equations (9) - (12) together with boundary conditions (13) are solved using Runge- Kutta fourth order method in conjunction with shooting technique. The results for velocity distribution, micro-rotation distribution, temperature distribution, magnetic distribution are presented graphically in figure (2) to (19) with the variation of different parameters. Initially the numerical value of different parameters are taken as $\quad \mathrm{P}_{\mathrm{m}}=0.5 \quad, \quad \mathrm{R}_{\mathrm{e}}=0.5, \quad \mathrm{M}=1, \mathrm{E}_{\mathrm{c}}=0.01, \mathrm{P}_{\mathrm{r}}=0.72$, $\theta_{\mathrm{k}}=2, \theta_{\mathrm{r}}=3, \mathrm{~J}=.1, \Delta=0.5, \Delta_{1}=0.3$ etc. The figures (2) to (8) display the variation in velocity profile for different parameters. The velocity of the fluid increases with the increasing value of the coupling constant $\Delta$ (Fig: 2), magnetic prandtl No. $\mathrm{P}_{\mathrm{m}}$. (Fig:5) and mixed convection parameter $\zeta$ (Fig:8) but it has been observed that velocity decreases with increasing values of magnetic M(Fig:4). It is because that the application of transverse magnetic field will result a resistive force (Lorentz force) which tends to resist the fluid flow and thus reducing its velocity. From Fig: 6 and Fig: 7, it can be observed that velocity does not vary significantly with the variation of viscosity parameter $\theta_{\mathrm{r}}$ and thermal conductivity parameter $\theta_{\mathrm{k}}$.

The variation of dimensionless temperature profile for various parameters is represented by figure (9) to (13). It is seen that temperature profile decreases due to increasing value of unsteady parameter $\mathrm{A}$, mixed convection parameter, magnetic $f^{\prime}(\eta)=1, f(\eta)=0, h(\eta)=0, \theta(\eta)=1, g(\eta)=1$ at $\eta=$ permeability, viscosity parameter (Fig:8,13) and increases for $f^{\prime}(\eta) \rightarrow 0, h(\eta) \rightarrow 0, g(\eta) \rightarrow 0, \theta(\eta) \rightarrow 0$ increasing value of $\mathrm{M}$ and $\theta_{\mathrm{k}}$ (Fig:9 and 11)

\section{at $\eta \rightarrow$}

The micro-rotation profile for various parameters are displayed in the figure (14) to (17). It is observed that microrotation have largely effect due to the variation of unsteady 
parameter $\mathrm{A}$, coupling constant $\Delta$, magnetic parameter $\mathrm{M}$. In the variation of viscosity parameter micro-rotation does not vary significantly (Fig: 17 ).

Figure (18) and (19) represent the effect of magnetic field. In that graphical representation it has been seen that due to increasing value of magnetic parameter the effect of magnetic field increasing and with the increasing value of magnetic prandtl's No., the effect of magnetic field decreasing significantly.

The missing values $f^{\prime \prime}(0), \theta^{\prime}(0), \mathrm{h}^{\prime}(0), \mathrm{g}^{\prime}(0)$ and co-efficient of skin friction $C_{f}$ i.e., the wall shear stress and Nusselt No $N_{u}$ which represents the heat transfer rate are given by

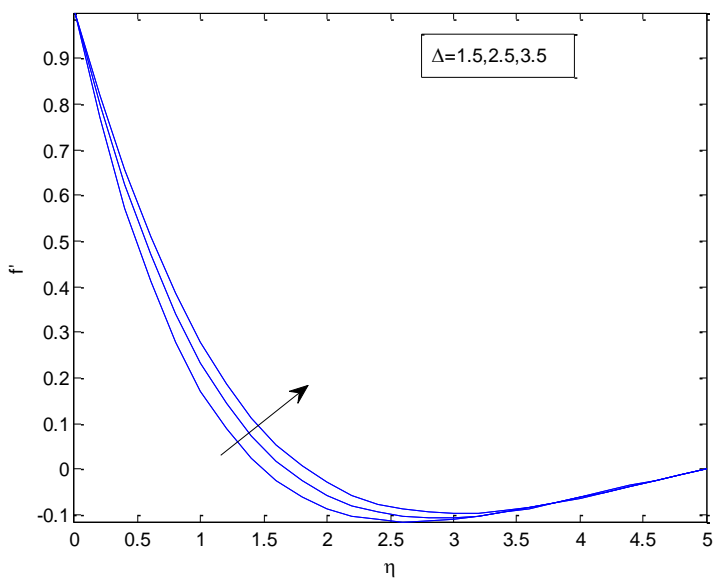

Fig: 2

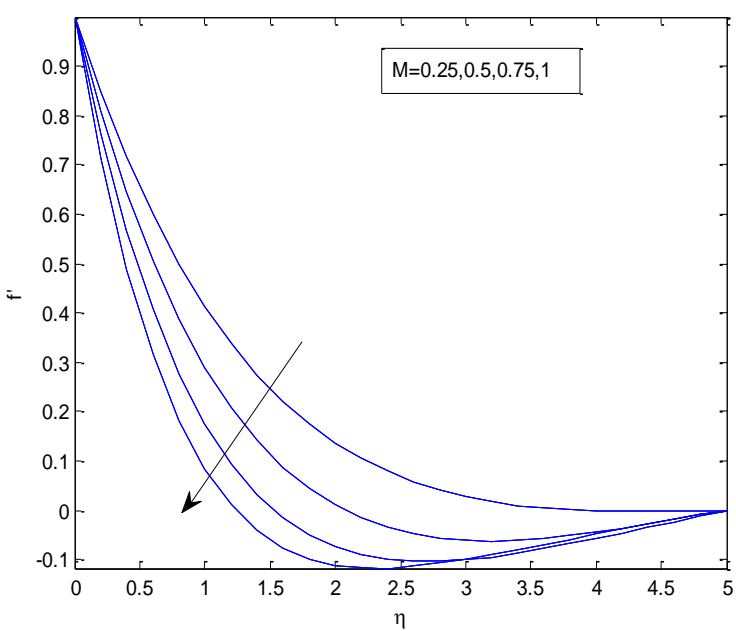

Fig:4 table: 1 to table: 5 for various combinations of parameters. In table :1and 2 it is observed that with the increasing value of thermal conductivity and viscosity parameter $f^{\prime \prime}(0)$, $\mathrm{g}^{\prime}(0), C_{f}, N_{u}$ decreases but $\theta^{\prime}(0), \mathrm{h}^{\prime}(0)$ increases. Table:4 gives the increasing values of $N_{u}$ and $C_{f}$ when both the values of $T_{r}$ and unsteady parameter increases. Similarly observing the tables: 3 to 5 it has been observed that $C_{f}$ decreases but $N_{u}$ increases due to increasing value of micropolar parameter $\Delta$, unsteady parameter $\mathrm{A}$, thermal conductivity and viscosity parameter.

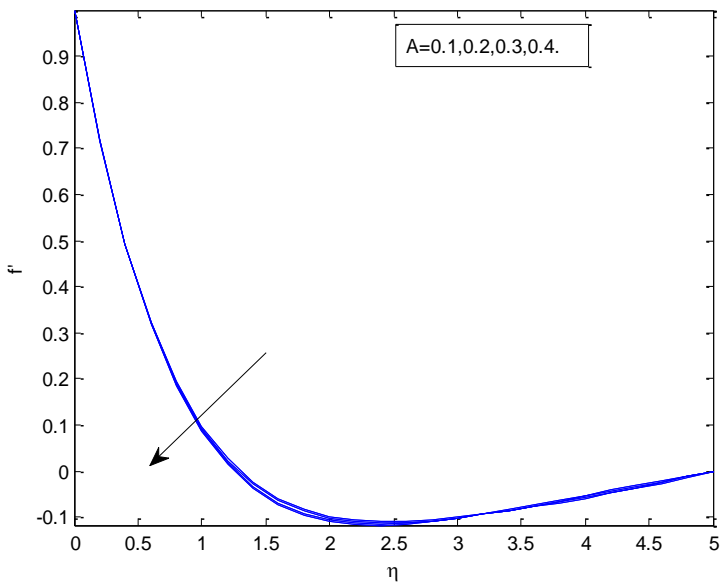

Fig : 3

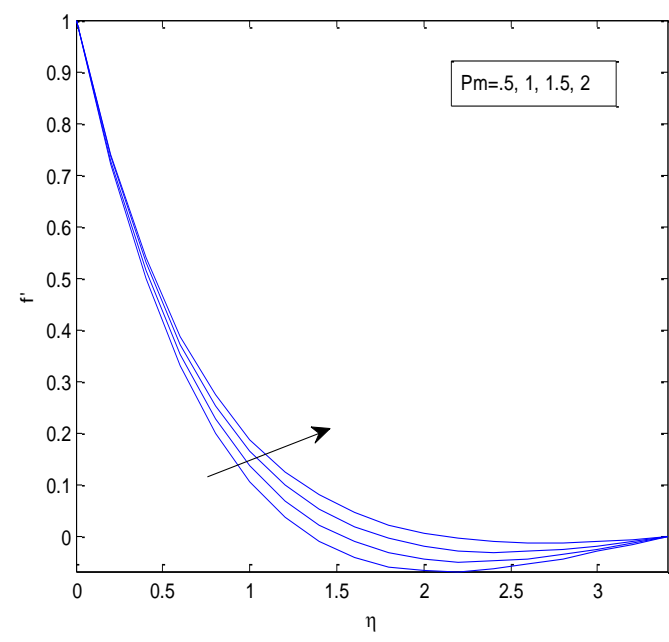

Fig: 5 


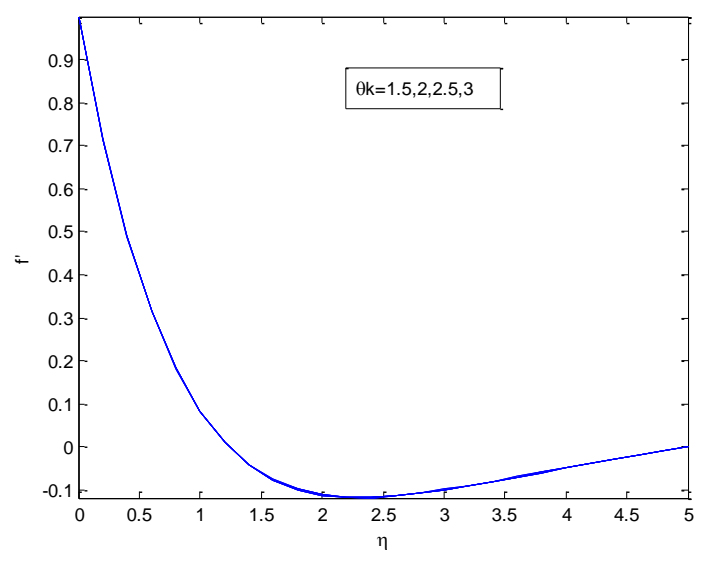

Fig: 6

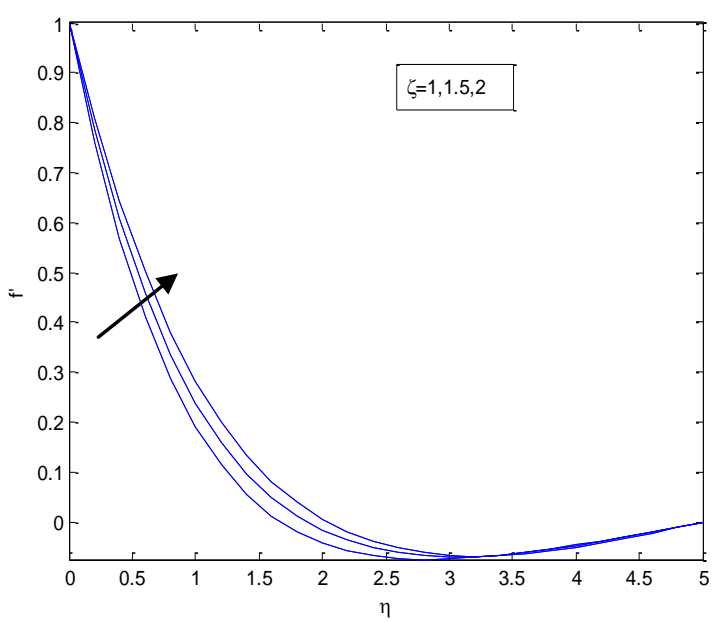

Fig: 8

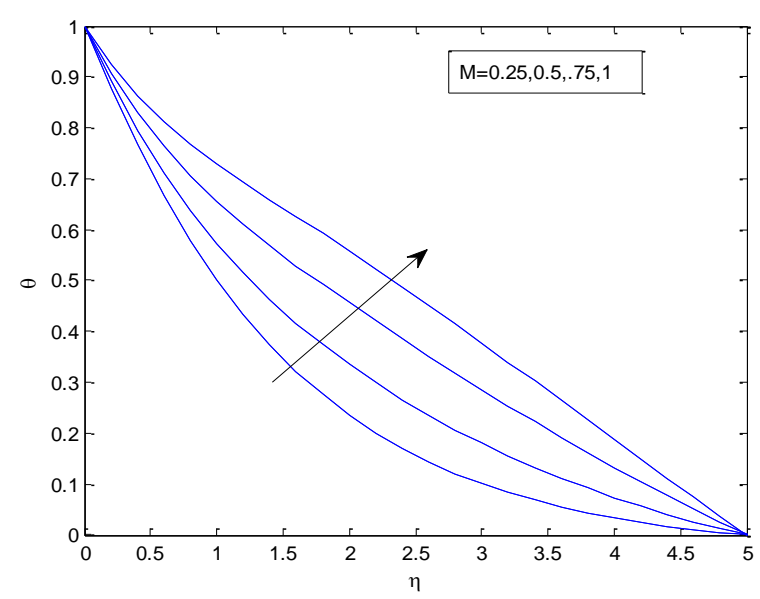

Fig: 10

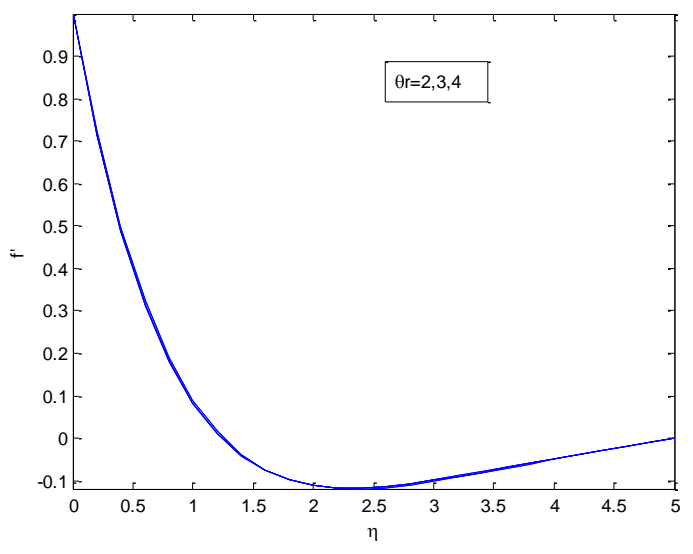

Fig: 7

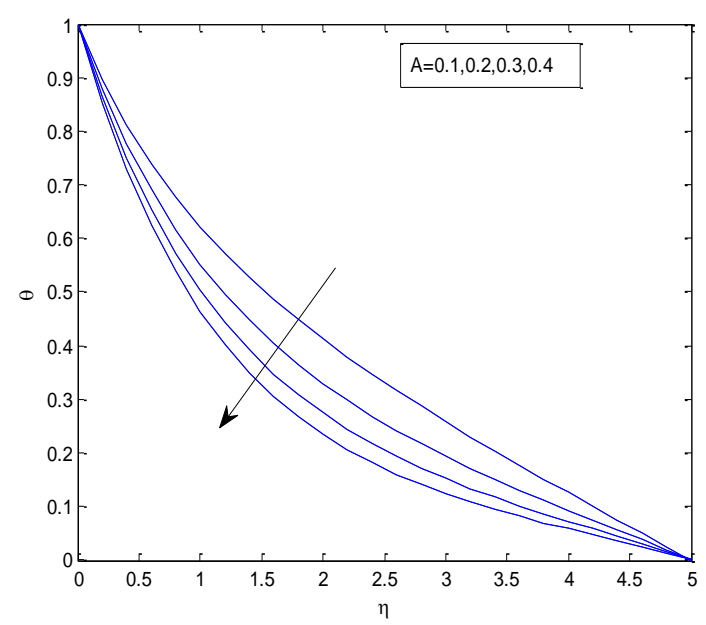

Fig: 9

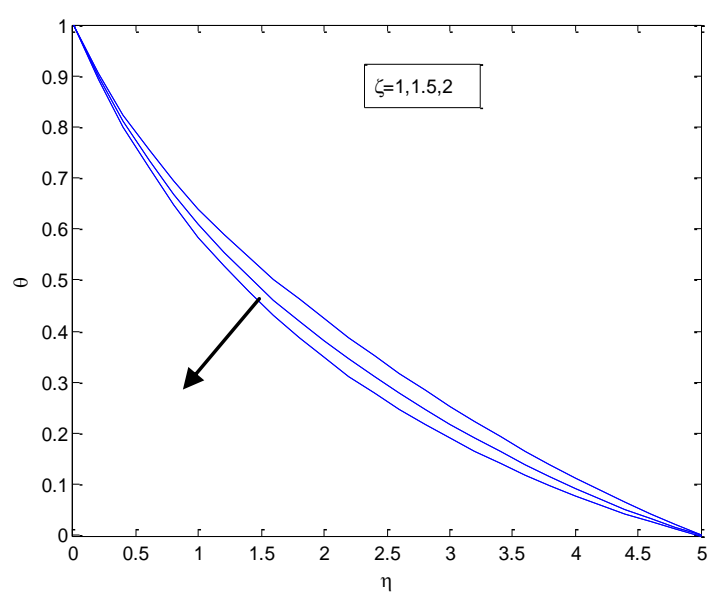

Fig: 11 


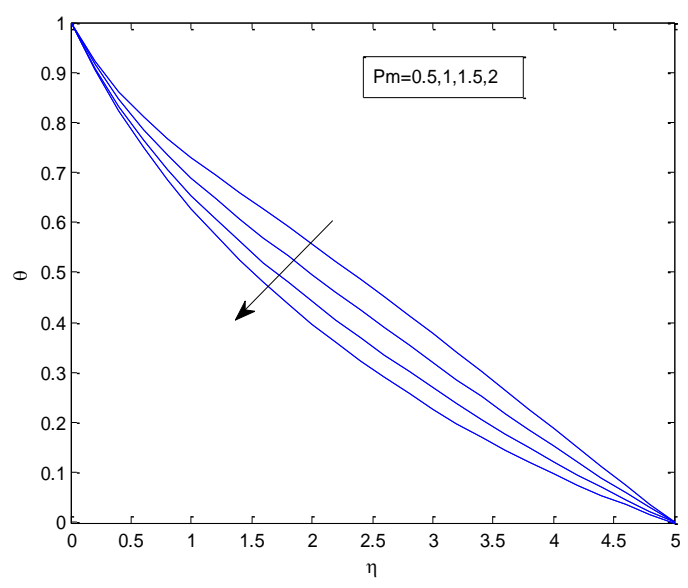

Fig: 12

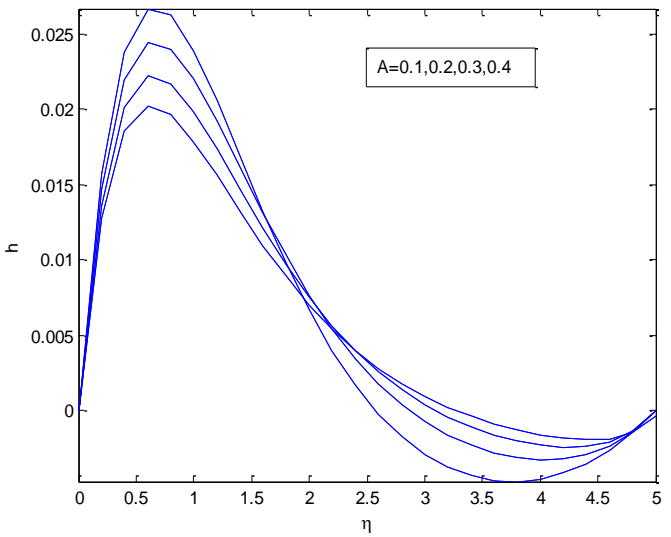

Fig: 14

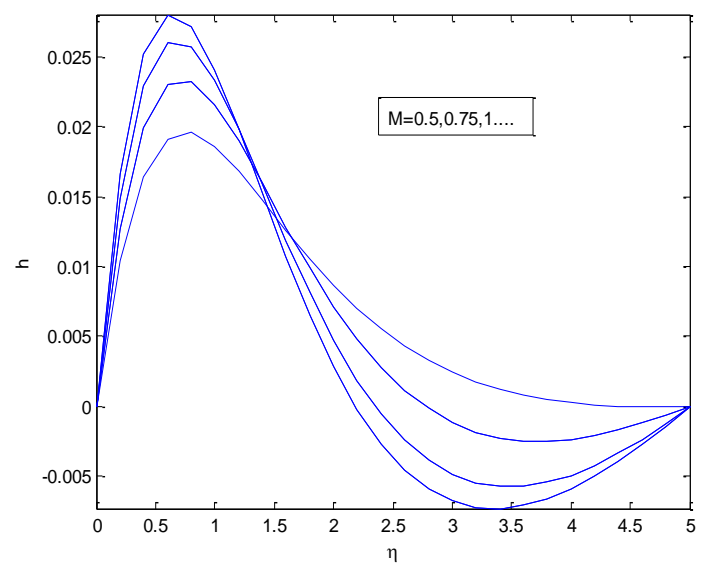

Fig: 16

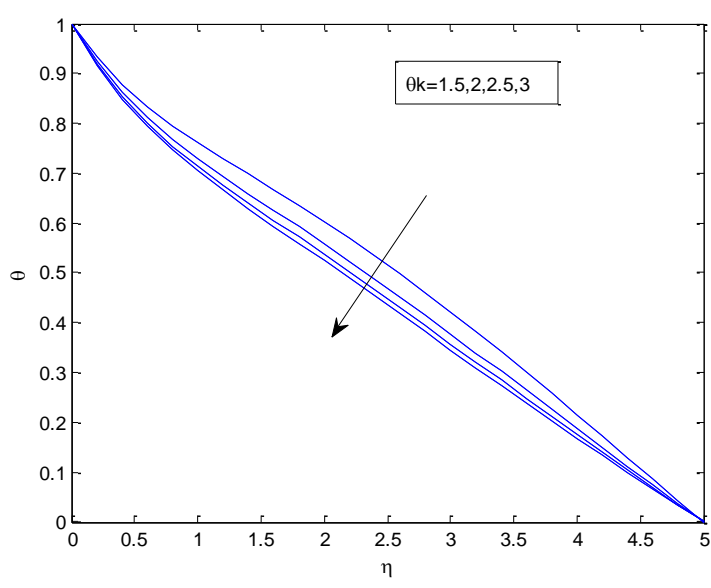

Fig: 13

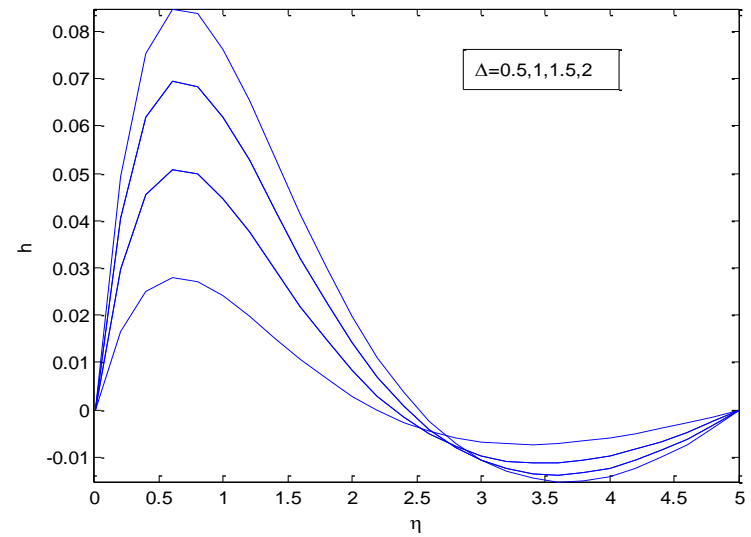

Fig: 15

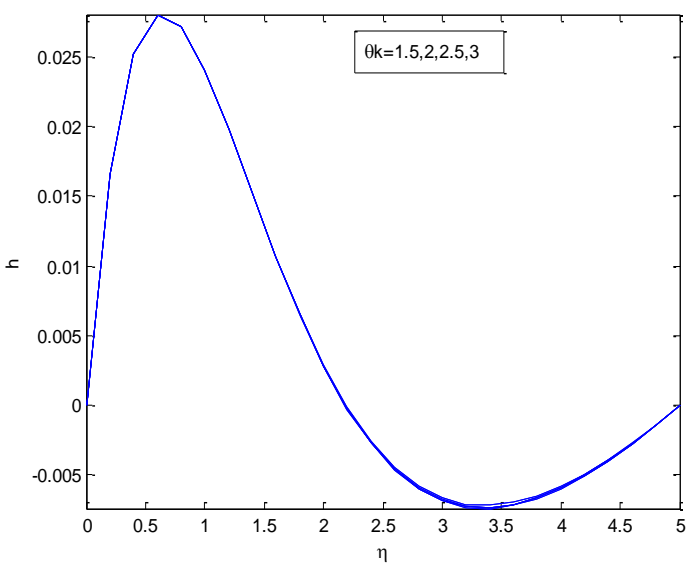

Fig:17 


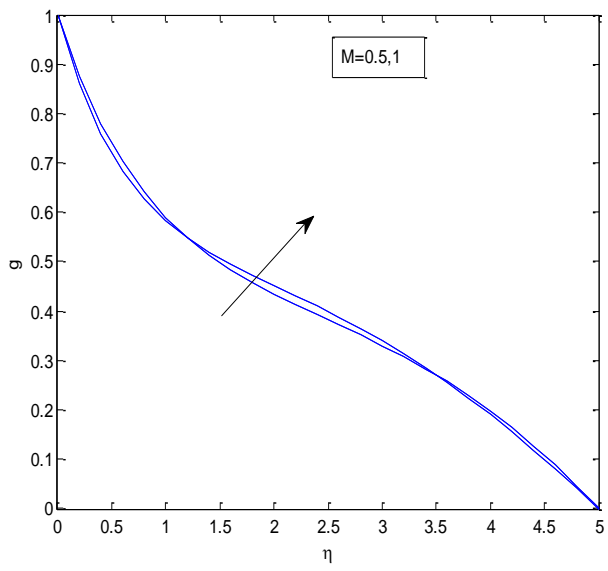

Fig: 18

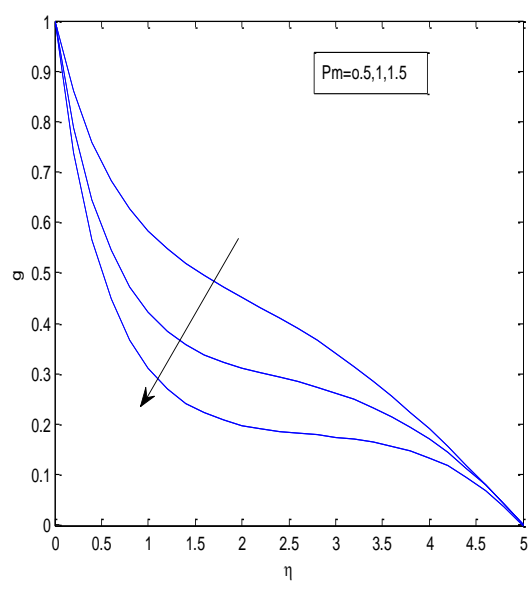

Fig: 19

Table 1:

\begin{tabular}{|l|l|l|l|l|l|l|l|}
\hline$\theta \mathrm{k}$ & $\mathrm{M}$ & $\mathrm{f}^{\prime}(0)$ & $\theta^{\prime}$ & $\mathrm{h}^{\prime}$ & $\mathrm{g}^{\prime}$ & $\mathrm{cf}$ & $\mathrm{Nu}$ \\
\hline \multirow{5}{*}{2} & 0.25 & -0.80267 & -0.64442 & 0.064622 & -0.60804 & -2.40802 & 0.644418 \\
\cline { 2 - 8 } & 0.5 & -1.02385 & -0.58123 & 0.079657 & -0.69762 & -3.07154 & 0.58123 \\
\cline { 2 - 8 } & 0.751 & -1.29471 & -0.50321 & 0.094434 & -0.7722 & -3.88412 & 0.503209 \\
\cline { 2 - 8 } & 1 & -1.58548 & -0.42851 & 0.107329 & -0.82585 & -4.75645 & 0.428507 \\
\hline \multirow{4}{*}{3} & 0.25 & -0.80026 & -0.72041 & 0.06472 & -0.60869 & -2.40079 & 0.720411 \\
\cline { 2 - 8 } & 0.5 & -1.02057 & -0.64597 & 0.079695 & -0.69803 & -3.06172 & 0.645967 \\
\cline { 2 - 8 } & 0.751 & -1.29076 & -0.55565 & 0.094416 & -0.77237 & -3.87229 & 0.555647 \\
\cline { 2 - 8 } & 1 & -1.58118 & -0.47152 & 0.107282 & -0.82588 & -4.74354 & 0.471522 \\
\hline \multirow{4}{*}{4} & 0.25 & -0.79925 & -0.75333 & 0.064733 & -0.60897 & -2.39775 & 0.753302 \\
\cline { 2 - 8 } & 0.5 & -1.01919 & -0.67391 & 0.079712 & -0.69821 & -3.05758 & 0.673909 \\
\cline { 2 - 8 } & 0.751 & -1.28909 & -0.57829 & 0.097708 & -0.772243 & -3.86726 & 0.578294 \\
\cline { 2 - 8 } & 1 & -1.57934 & -0.49021 & 0.107262 & -0.82589 & -4.73801 & 0.490206 \\
\hline
\end{tabular}

Table 2:

\begin{tabular}{|l|l|l|l|l|l|l|l|}
\hline \multirow{\theta}{*}{$\mathrm{r}$} & $\mathrm{M}$ & $\mathrm{f}^{\prime \prime}(0)$ & $\mathrm{\theta}^{\prime}$ & $\mathrm{h}^{\prime}$ & $\mathrm{g}^{\prime}$ & $\mathrm{cf}$ & $\mathrm{Nu}$ \\
\hline \multirow{5}{*}{2} & 0.25 & -0.74779 & -0.6505 & 0.062835 & -0.59911 & -2.24336 & 0.650501 \\
\cline { 2 - 8 } & 0.5 & -0.96517 & -0.58828 & 0.077844 & -0.68952 & -2.89552 & 0.588197 \\
\cline { 2 - 8 } & 0.751 & -1.23777 & -0.50984 & 0.092854 & -0.76614 & -3.71332 & 0.509843 \\
\cline { 2 - 8 } & 1 & -1.53387 & -0.43359 & 0.106085 & -0.82174 & -4.6016 & 0.433586 \\
\hline \multirow{4}{*}{3} & 0.25 & -0.80267 & -0.64442 & 0.064622 & -0.60804 & -2.40802 & 0.644418 \\
\cline { 2 - 8 } & 0.5 & -1.02385 & -0.58123 & 0.079657 & -0.69762 & -3.07154 & 0.58123 \\
\cline { 2 - 8 } & 0.751 & -1.29471 & -0.50321 & 0.094434 & -0.7722 & -3.88412 & 0.503209 \\
\cline { 2 - 8 } & 1 & -1.58848 & -0.42851 & 0.107329 & -0.82585 & -4.75645 & 0.428507 \\
\cline { 2 - 8 } & 0.25 & -0.82385 & -0.64192 & 0.065348 & -0.6117 & -2.47165 & 0.641917 \\
\cline { 2 - 8 } & 0.5 & -1.04577 & -0.57843 & 0.080366 & -0.70079 & -3.13731 & 0.0 .578434 \\
\cline { 2 - 8 } & 0.751 & -1.31526 & -0.5007 & 0.095022 & -0.77445 & -3.94579 & 0.500702 \\
\cline { 2 - 8 } & 1 & -1.60366 & -0.42667 & 0.107776 & -0.82732 & -4.81099 & 0.426666 \\
\hline
\end{tabular}


Table 3:

\begin{tabular}{|l|l|l|l|l|l|l|l|}
\hline$\theta_{\mathrm{r}}$ & $\Delta$ & $\mathrm{f}^{\prime \prime}(0)$ & $\mathrm{f}^{\prime}$ & $\mathrm{h}^{\prime}$ & $\mathrm{g}^{\prime}$ & $\mathrm{cf}$ & $\mathrm{Nu}$ \\
\hline \multirow{5}{*}{2} & 1 & -1.34469 & -0.46893 & 0.189405 & -0.79308 & -5.37875 & 0.468925 \\
\cline { 2 - 8 } & 2 & -1.10911 & -0.51592 & 0.312884 & -0.74979 & -6.65466 & 0.515922 \\
\cline { 2 - 8 } & 3 & -0.96231 & -0.54571 & 0.401285 & -0.71764 & -7.69845 & 0.545703 \\
\hline \multirow{3}{*}{3} & 1 & -1.38582 & -0.46419 & 0.191493 & -0.79708 & -5.54318 & 0.464193 \\
\cline { 2 - 8 } & 2 & -1.13824 & -0.51199 & 0.316163 & -0.75348 & -6.82941 & 0.511993 \\
\cline { 2 - 8 } & 3 & -0.98471 & -0.54244 & 0.40532 & -0.72111 & -7.87767 & 0.54244 \\
\hline \multirow{3}{*}{4} & 1 & -1.40043 & -0.46244 & 0.19229 & -0.79855 & -5.60172 & 0.462437 \\
\cline { 2 - 8 } & 2 & -1.14878 & -0.51049 & 0.31742 & -0.75487 & -6.89266 & 0.51049 \\
\cline { 2 - 8 } & 3 & -0.99292 & -0.54117 & 0.406868 & -0.7223 & -7.94333 & 0.541168 \\
\hline
\end{tabular}

Table 4:

\begin{tabular}{|l|l|l|l|l|l|l|l|}
\hline \multirow{\theta}{*}{$\mathrm{r}$} & $\mathrm{A}$ & $\mathrm{f}^{\prime \prime}(0)$ & $\mathrm{\theta}^{\prime}$ & $\mathrm{h}^{\prime}$ & $\mathrm{g}^{\prime}$ & $\mathrm{cf}$ & $\mathrm{Nu}$ \\
\hline \multirow{4}{*}{2} & 0.1 & -1.5141 & -0.56579 & 0.101259 & -0.83495 & -4.54229 & 0.56579 \\
\cline { 2 - 8 } & 0.2 & -1.50662 & -0.65885 & 0.095455 & -0.84852 & -4.51987 & 0.658852 \\
\cline { 2 - 8 } & 0.3 & -1.5045 & -0.73404 & 0.090112 & -0.86207 & -4.5135 & 0.73404 \\
\cline { 2 - 8 } & 0.4 & -1.50535 & -0.79884 & 0.85531 & -0.87555 & -4.51605 & 0.798835 \\
\hline \multirow{4}{*}{3} & 0.1 & -1.58027 & -0.5608 & 0.102705 & -0.84037 & -4.7408 & 0.560804 \\
\cline { 2 - 8 } & 0.2 & -1.58146 & -0.65416 & 0.096986 & -0.85467 & -4.74439 & 0.654164 \\
\cline { 2 - 8 } & 0.3 & -1.58553 & -0.72964 & 0.09171 & -0.86874 & -4.75658 & 0.72964 \\
\cline { 2 - 8 } & 0.4 & -1.59122 & -0.79469 & 0.087184 & -0.88261 & -4.77367 & 0.794689 \\
\hline \multirow{4}{*}{4} & 0.1 & -1.60422 & -0.55893 & 0.103244 & -0.84239 & -4.81267 & 0.558926 \\
\cline { 2 - 8 } & 0.2 & -1.60898 & -0.65237 & 0.097569 & -0.85701 & -4.82694 & 0.652367 \\
\cline { 2 - 8 } & 0.3 & -1.61563 & -0.72793 & 0.092327 & -0.87131 & -4.8469 & 0.727934 \\
\cline { 2 - 8 } & 0.4 & -1.62338 & -0.79307 & 0.087828 & -0.88534 & -4.87013 & 0.793068 \\
\hline
\end{tabular}

Table 5:

\begin{tabular}{|l|l|l|l|l|l|l|l|}
\hline \multirow{\theta}{*}{$\mathrm{k}$} & $\mathrm{A}$ & $\mathrm{f}^{\prime \prime}(0)$ & $\mathrm{f}^{\prime}$ & $\mathrm{h}^{\prime}$ & $\mathrm{g}^{\prime}$ & $\mathrm{cf}$ & $\mathrm{Nu}$ \\
\hline \multirow{4}{*}{2} & 0.1 & -1.58027 & -0.5608 & 0.102705 & -0.84037 & -4.7408 & 0.560804 \\
\cline { 2 - 8 } & 0.2 & -1.58146 & -0.65416 & 0.096986 & -0.85467 & -4.74439 & 0.654164 \\
\cline { 2 - 8 } & 0.3 & -1.58553 & -0.72964 & 0.09171 & -0.68674 & -4.75658 & 0.72964 \\
\cline { 2 - 8 } & 0.4 & -1.59122 & -0.79469 & 0.087184 & -0.8826 & -4.77367 & 0.794689 \\
\hline \multirow{4}{*}{3} & 0.1 & -1.5757 & -0.6166 & 0.102694 & -0.84037 & -4.72709 & 0.616595 \\
\cline { 2 - 8 } & 0.2 & -1.57653 & -0.72092 & 0.096964 & -0.85466 & -4.7296 & 0.720923 \\
\cline { 2 - 8 } & 0.3 & -1.58033 & -0.80538 & 0.091696 & -0.86873 & -4.74099 & 0.805379 \\
\cline { 2 - 8 } & 0.4 & -1.58582 & -0.87805 & 0.087168 & -0.88259 & -4.75746 & 0.878053 \\
\hline \multirow{4}{*}{4} & 0.1 & -1.57377 & -0.64041 & 0.10269 & -0.84037 & -4.72131 & 0.640408 \\
\cline { 2 - 8 } & 0.2 & -1.57447 & -0.74933 & 0.096971 & -0.85466 & -4.72341 & 0.749328 \\
\cline { 2 - 8 } & 0.3 & -1.57816 & -0.8376 & 0.091691 & -0.86873 & -4.73447 & 0.837596 \\
\cline { 2 - 8 } & 0.4 & -1.58356 & -0.91352 & 0.087162 & -0.88259 & -4.75069 & 0.913518 \\
\hline
\end{tabular}




\section{CONCLUSION}

Throughout this study it is being observed that within the boundary layer thermal conductivity and viscosity parameter along with other parameters have a significant effect on velocity, micro-rotation, temperature distribution and magnetic field.

The main results can be summarized as:

(1) With the variation of Unsteadiness parameter A the velocity profile and temperature profile decreases.

(2) With the increasing value of mixed convection parameter velocity profile increases but temperature profile decreases.

(3) The effect of increasing value of magnetic parameter $\mathrm{M}$ velocity profile decreases and temperature profile increases.

(4) Micro - rotation distinctly effected due to the variation of parameter $\mathrm{A}, \mathrm{M}, \Delta$. etc.

(5) The Nusselt No. and Skin friction increasing due to the increasing value viscosity parameter and unsteady parameters.

\section{ACKNOWLEDGEMENTS}

Authors duly offer gratitude to the respected reviewers for their valuable suggestions in enriching the quality of the paper.

\section{REFERENCES}

[1] A .C Eringen, "Theory of simple microfluids", Int'l. J. Sci., pp.205-217, (1964).

[2] A.C.Eringen, "Theory of micropolar fluids", J. Math. Mech. 16, pp.1-18, (1966).

[3] B.C. Sakiadis, "Boundary-layer behaviour on continuous solid surface", J. AI Che, Vol. 7, pp. 26-28, (1961).

[4] F.C.Lai. \& F.A. Kulacki, "The effect of variable viscosity and mass transfer along a vertical surface in a saturated porous medium.", Int. J. Heat and Mass transfer, Vol.33, pp.1028-1031, (1990).

[5] G.C.Hazarika and B.Phukan, "Effect of variable viscosity and thermal conductivity on MHD flow of micropolar fluid in a continuous moving flat plate.” IJCA, Vol.122, pp. 29-37, (2015).

[6] G. Lukaszewicz, "MicropolaTheory and application.", Birkhausser Bostan, (1990).

[7] J. Peddison and R.P. McNitt, "Boundary layer theory for micropolar fluid.”, Recent Adv.Eng.Sci.,Vol.5, pp.405426, (1970).

[8] K .Das, P.R. Durai, P.K.Kundoo, "Nanofluid flow over an unsteady stretching surface in presence of thermal radiation.”, Alexandria Eng J. 53(3), pp.737-795, (2014).

[9] Lasker Ershad Ali, Ariful Islam, Nazmul Islam, "Investigate micropolar fluid behavior on mass transfer flow with constant heat and mass fluxes by finite difference method.”, American J. of Appl. Math.(3), pp.157-168, (2015).

[10] M. A. El-Aziz, "Mixed convection flow of a micropolar fluid from an unsteady stretching surface with viscous dissipation”, J. of Egypt. Math. Soc. Vol. 21, pp.385394, (2013).

[11] P.O Olanrewaju., G.T Okedayo, J.A Gbadeyan, "Effect of thermal radiation on magnetohydrodynamics flow of micropolar fluid towards a stagnation point on a vertical plate.”, Int. J. Appl. Sc. \& Tech, Vol , No pp. 219-230, (2011).

[12] P.M Thakur. and G.C Hazarika, "Effect of variable viscosity and thermal conductivity on unsteady free convection heat and mass transfer MHD flow of micropolar fluid with constant heat flux through porous medium.” Int.J. Com.Appl.Vol-8, pp. 8875-8887, (2015)

[13] R.S.R. Gorla, H.S Takhar, A Slaouti, "Magneto hydrodynamic free convection boundary layer flow of a thermo micropolar fluid over a vertical plate.", Int. J. Eng.Sci.Vol-30, pp.349-358, (1992).

[14] T. Hayat, Z. Abbas ,T. Javed, "Mixed convection flow of a micropolar fluid over a non linearl stretchingsheet.”,Physics LetterA,372, Issue 5 pp. 637-647, (2008).

[15] T. Ariman, M.A. Trurk, N.D. Sylvester, "Microcontinuum fluid mechanics, a review.", Int J.Eng.Sci, pp.905-930, (1974). 